\title{
Densification and mechanical properties of mullite-SiC nanocomposites synthesized through sol-gel coated precursors
}

\author{
K G K WARRIER, G M ANIL KUMAR and S ANANTHAKUMAR* \\ Ceramics Division, Regional Research Laboratory, Thiruvananthapuram 695 019, India
}

\begin{abstract}
Mullite-SiC nanocomposites are synthesized by introducing surface modified sol-gel mullite coated $\mathrm{SiC}$ particles in the matrix and densification and associated microstructural features of such precursor are reported. Nanosize $\mathrm{SiC}$ (average size $180 \mathrm{~nm}$ ) surface was first provided with a mullite precursor coating which was characterized by the $X$-ray analysis and TEM. An average coating thickness of $120 \mathrm{~nm}$ was obtained on the $\mathrm{SiC}$ particles. The green compacts obtained by cold isostatic pressing were sintered in the range $1500-1700^{\circ} \mathrm{C}$ under pressureless sintering in the $\mathrm{N}_{2}$ atmosphere. The percentage of the theoretical sintered density decreases with increase in SiC content. A maximum sintered density of $97 \%$ was achieved for mullite-5 vol.\% SiC. The fractograph of the sintered composite showed a highly dense, fine grained microstructure with the $\mathrm{SiC}$ particles uniformly distributed along the grains as well as at the grain boundaries inside the mullite. The Vicker's microhardness of mullite-5 vol.\% SiC composite was measured as $1320 \mathrm{~kg} / \mathrm{mm}^{2}$ under an applied indentation load of $500 \mathrm{~g}$. This value gradually decreased with an increase in $\mathrm{SiC}$ content.
\end{abstract}

Keywords. Mullite-SiC nanocomposites; sol-gel; microstructure; Vicker's microhardness.

\section{Introduction}

The ceramic matrix nanocomposites, which involve a uniform dispersion of nanometer size second phase particles in a ceramic matrix, are a class of special materials, widely used for engineering applications (Niihara 1991; Komerneni 1992). Such composites are reported to have high strength and toughness due to the dissipation of the applied strain energy to several orders of magnitude $\mathrm{CHu}$ and Rahaman 1992) and minimize the fracture surface energy, $\gamma_{\mathrm{IC}}$. The dispersed second phase is believed to control the inherent flaws, especially at the grain boundaries and thus reduces the residual stresses at the interfaces of the matrix (Choa et al 1994). The alumina dispersed with nano $\mathrm{SiC}$ is extensively studied by many researchers (Thompson et al 1995; Bhaduri and Bhaduri 1998). Alumina containing $5 \mathrm{vol} \% \mathrm{SiC}$ particles showed an increase of fracture strength $(\sigma)$ from $320 \mathrm{MPa}$ to $1050 \mathrm{MPa}$ and fracture toughness $\left(K_{\mathrm{IC}}\right)$ from $3 \cdot 2 \mathrm{MPa} \cdot \mathrm{m}^{1 / 2}$ to 4.7 MPa.m ${ }^{1 / 2}$ (Mitchell and De Jonghe 1995). The proposed mechanism for such an improvement of fracture strength and toughness are (i) particle bridging, (ii) crack pinning and crack deflection and (iii) stress induced micro cracking (Warrier et al 1996). The most important criteria for such properties are uniform distribution of the second phase particles in the matrix and minimum agglomeration of the dispersed phases, which will reduce the heterogeneity, which may lead to partial densification $(\mathrm{Hu}$ and Rahaman 1993). The conventional methods of processing

\footnotetext{
*Author for correspondence
}

are hot pressing and hot isostatic pressing, that are mostly used and widely reported (Kapolnek and De Jonghe 1991). Although, the hot pressed alumina-SiC ceramics have much narrower flaw size population, during mechanical operations, the morphology and flaw size rapidly changes and produce crack like voids due to $\mathrm{SiC}$ agglomeration (Wang et al 1996). Recently, the pressureless sintering of alumina-SiC nanocomposites is reported in which a thin layer of alumina precursor coating is achieved by hybrid polymer-powder processing which resulted in a highly dense microstructure with reduced flaws (Kanpuri et al 1996). Other important ceramicmatrix nanocomposites reported are alumina-SiC, $\mathrm{MgO}-$ SiC and mullite-SiC (Pezzotti and Saki 1994; Saka et al 1995; Wang 1996).

In the present work, a sol-gel synthesis of mullite-SiC nanocomposite is reported and the densification analysed by its microstructural features are presented. The room temperature microhardness is also studied and compared with sol-gel mullite without $\mathrm{SiC}$ reinforcement.

\section{Experimental}

\subsection{Activation of SiC powder}

As received $\mathrm{SiC}$ powder ( $180 \mathrm{~nm}$ size), Ibiden, Ogaki (Japan) was washed with dilute $1 \%$ HF solution to remove possible traces of silica associated with the powder. The HF treated powder was then washed thoroughly with double distilled water, finally with acetone and dried. Further, 
this powder was thermally activated at $250^{\circ} \mathrm{C}$ for $3 \mathrm{~h}$ in air. This activated $\mathrm{SiC}$ powder was used for the synthesis of mullite-SiC nanocomposite precursors.

\subsection{Preparation of mullite coated SiC nanocomposite precursor}

Boehmite sol prepared by the hydrolysis of $\mathrm{Al}\left(\mathrm{NO}_{3}\right)_{3} \cdot 9 \mathrm{H}_{2} \mathrm{O}$ and tetraethylorthosilicate (TEOS) were used as alumina and silica sources respectively. Four different mullite-SiC nanocomposite precursors were prepared by varying the amount of $\mathrm{SiC}$ loading in the mullite matrix i.e. precursor containing 5 vol.\% SiC, 10 vol.\% SiC, 15 vol.\% SiC and 20 vol.\% SiC. In a typical experiment for the preparation of $30 \mathrm{~g}$ mullite 5 vol.\% SiC composite, $1.5 \mathrm{~g}$ of $\mathrm{SiC}$ was dispersed in $200 \mathrm{ml}$ of ethanol-water mixture $(1: 1)$. This was then ball milled for $\sim 5 \mathrm{~h}$ in a PVC container with alumina as the grinding media to get a good dispersion of $\mathrm{SiC}$ particles in the medium. The mullite precursor sol was prepared by mixing boehmite sol and TEOS. $1024 \mathrm{ml}$ of boehmite sol was taken and to this $27.6 \mathrm{ml}$ of TEOS was added dropwise with vigorous stirring. The mixture was stirred for about $5 \mathrm{~h}$ to result in a homogeneous distribution of alumina and silica species (to get $23.5 \mathrm{~g}$ mullite phase). To this mixture a $\mathrm{SiC}$ suspension was added, stirred for $1 \mathrm{~h}$ and the whole suspension with the dispersed $\mathrm{SiC}$ particles were flocculated to $\mathrm{pH} 7.5$ by the addition of dilute ammonia solution. The coated powders were filtered, washed and dried in an air oven at $80^{\circ} \mathrm{C}$. Similar experimental procedure was repeated for the preparation of $10 \mathrm{vol} \%, 15 \mathrm{vol} . \%$ and $20 \mathrm{vol} . \% \mathrm{SiC}-$ mullite composites.

The characterization of the mullite coating on the green samples as well as those calcined at $600^{\circ}$ and $800^{\circ} \mathrm{C}$ were carried out using a transmission electron microscope (TEM, Model: JEOL $100 \mathrm{CX}$ ). The TEM samples were prepared as follows:

A suspension containing coated $\mathrm{SiC}$ particles $(0 \cdot 5 \mathrm{wt} \%)$ was made in a percentage ethanol-isopropanol medium. A drop of the suspension was deposited on to a carbon coated TEM grid and dried under vacuum. The grid was observed under TEM. The composite precursors containing $\mathrm{SiC}$ particles were calcined at $1000^{\circ} \mathrm{C}$ in $\mathrm{N}_{2}$ atmosphere for $2 \mathrm{~h}$ with a heating rate of $5^{\circ} \mathrm{C} / \mathrm{min}$. The calcined powders were then ball milled in ethanol for $12 \mathrm{~h}$ and the hard agglomerates were removed by sedimentation and dried in an air oven at $50^{\circ} \mathrm{C}$. The dried powders were then compacted into bars of dimensions $40 \times 5 \times 4 \mathrm{~mm}$ by uniaxial pressing at $25 \mathrm{MPa}$ followed by cold isostatic pressing (CIP) at $500 \mathrm{MPa}$. The bars were then subjected to gas pressure sintering at $1550^{\circ}, 1650^{\circ}$ and $1700^{\circ} \mathrm{C}$ for a period of $1 \mathrm{~h}$ under $\mathrm{N}_{2}$ atmosphere in a graphite crucible over SiC powder bed. A gas pressure of 60 bar was applied at the sintering temperature. The sintered densities of the fired samples were measured by Archimedes' method with water as the reference liquid. The thermo- mechanical analysis of the samples was done (after calcining the coated powder at $1000^{\circ} \mathrm{C}$ in nitrogen atmosphere) in Netzsch dilatometer at a heating rate of $10^{\circ} \mathrm{C} / \mathrm{min}$ up to $1000^{\circ} \mathrm{C}$ and up to $1700^{\circ} \mathrm{C}$ at a heating rate of $30^{\circ} \mathrm{C} / \mathrm{min}$ in $\mathrm{N}_{2}$ atmosphere. XRD of samples were recorded in Philips PW-1710 diffractometer. The sintered composites were mounted in a polymer matrix and polished to get a smooth, crack free surface. The Vicker's microhardness was determined by indentation with varying load using Shimadzu microhardness tester.

\section{Results and discussion}

\subsection{Characterization of coating}

The coating on the SiC particles with the mullite precursor was first identified through analysing the intensities of the peaks in the XRD patterns of the uncoated SiC and mullite gel coated SiC. The XRD patterns of the uncoated $\mathrm{SiC}$ and mullite gel coated $\mathrm{SiC}$, and the same calcined at $600^{\circ} \mathrm{C}$ are presented in figure 1 . The intensities of the $\mathrm{SiC}$

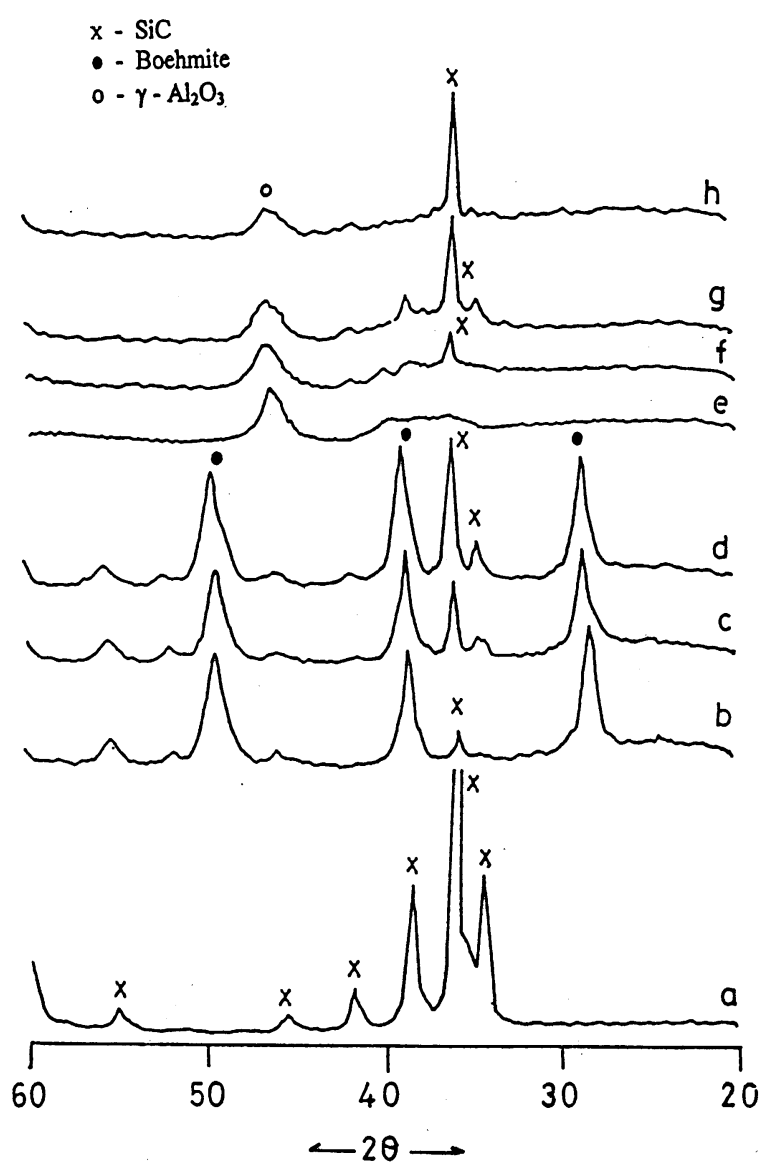

Figure 1. XRD patterns of sol-gel mullite coated $\mathrm{SiC}$ nanocomposites: a. $\mathrm{SiC}$ as received, b. mullite 5 vol. $\% \mathrm{SiC}$, c. mullite 15 vol. $\% \mathrm{SiC}$, d. mullite 20 vol. $\% \mathrm{SiC}$, e. sol-gel mullite $600^{\circ} \mathrm{C}$, f. mullite 5 vol. $\% \mathrm{SiC}-600^{\circ}$, g. mullite 15 vol. $\%$ $\mathrm{SiC}-600^{\circ}$ and $\mathrm{h}$. mullite 20 vol. $\% \mathrm{SiC}-600^{\circ} \mathrm{C}$. 
peaks were found to decrease on coating with the mullite precursor. However, the reduction in intensity decreased with increase in concentration of $\mathrm{SiC}$ particles from 520 vol.\%, which could have been due to the increase in $\mathrm{SiC}$ particle per unit area. TEM observation of the coated mullite-SiC precursor is presented in figure 2 .

The starting gel particle size of mullite precursor was about $100 \mathrm{~nm}$ and the coating was built up of 2-3 layer stacking over the $\mathrm{SiC}$ particles. This coating also appeared to be microporous. The gel crystallites were elongated in shape with a maximum length of $\sim 250 \mathrm{~nm}$ and thickness of $80-100 \mathrm{~nm}$. On calcination at $600^{\circ} \mathrm{C}$, there was a uniform shrinkage of the coating to an average size of $70 \mathrm{~nm}$. The coating also appeared to be denser. In any case, the method of the coating adopted in this procedure had been successful in obtaining fully coated $\mathrm{SiC}$ particles.

\subsection{Densification features}

The green compact densities were found to be $\sim 50 \%$ of the theoretical. The sintering behaviour of the sol-gel mullite coated $\mathrm{SiC}$ composite precursor was followed by dilatometry (figure 3).

The coated $\mathrm{SiC}$ precursor was preheated to $1000^{\circ} \mathrm{C}$ before subjecting it to the dilatometric measurements. The typical heating cycle followed for dilatometric analysis



Figure 2. TEM image of sol-gel mullite coated SiC. was $10^{\circ} \mathrm{C} / \mathrm{min}$ up to $1000^{\circ} \mathrm{C}$ and $30^{\circ} \mathrm{C} / \mathrm{min}$ up to $1700^{\circ} \mathrm{C}$ in a $\mathrm{N}_{2}$ atmosphere and soaking for $1 \mathrm{~h}$ at that environment. The extent of densification decreased with increasing vol.\% SiC. The composite containing 5 vol.\% SiC showed no change up to $1000^{\circ} \mathrm{C}$ and no shrinkage was observed. The shrinkage started approximately around $1200^{\circ} \mathrm{C}$ and proceeded faster in the range $1270-1300^{\circ} \mathrm{C}$.

Mullitization of the precursor phase was expected at such sintering temperatures. The maximum shrinkage occurred in this narrow range which indicated a fast rate of sintering. In the case of $10 \mathrm{vol} \% \mathrm{SiC}$, the densification started at $1220^{\circ} \mathrm{C}$ and the rate of densification was maximum between 1300 and $1350^{\circ} \mathrm{C}$. The mullite $\mathrm{SiC}$ nanocomposite precursor with high vol. $\% \mathrm{SiC}$ required additional driving force for complete densification. $\mathrm{Mu}-$ llite-10 vol.\% $\mathrm{SiC}$ had a maximum shrinkage of $17.5 \%$ in the range $1000-1350^{\circ} \mathrm{C}$. The maximum shrinkage in a sample with $15 \mathrm{vol} \%$ and $20 \mathrm{vol} \% \mathrm{SiC}$ was less than $15 \%$. Qualitative observations indicated very low level of oxidation of the $\mathrm{SiC}$ phase. Since the thermal expansion coefficient of mullite and $\mathrm{SiC}$ is nearly identical, the interface mismatch between mullite-SiC was avoided. The reactive alumina present in the coating reacted only with the silica which formed a liquid phase at lower temperatures that favoured the densification process. The sintered densities of the coated nanocomposite samples at different temperatures are presented in table 1 . The results indicated that the densities of the composite were strongly dependent on the volume fraction of the particulate dispersions.

In all the cases sintering had been carried out under $\mathrm{N}_{2}$ atmosphere mainly to avoid the oxidation of SiC. The original property of the composite could have been lost due to oxidation of SiC. Considering the sintered densities of the samples, there was a decrease in density with the increase in vol.\% of SiC. This could be due to the clustering of the reinforcing particles to form networks, which hindered the densification of the composite (Kanpuri et al 1996).

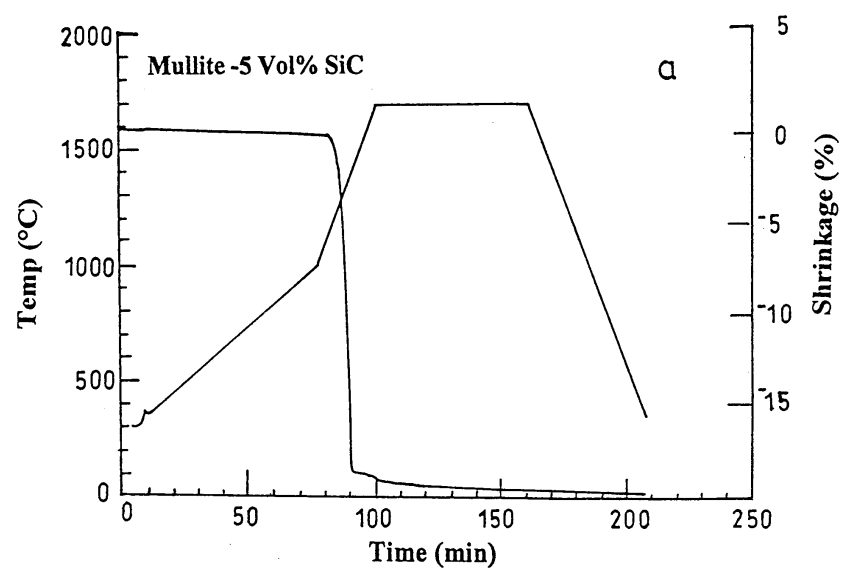

Figure 3. Dilatometric curve of mullite-SiC nanocomposites. 
Table 1. \% Theoretical sintered density of mullite-SiC composite at various temperatures.

\begin{tabular}{llccc}
\hline & & \multicolumn{3}{c}{$\%$ Theoretical sintered density } \\
\cline { 3 - 5 } $\begin{array}{l}\text { Sample } \\
\text { no. }\end{array}$ & Samples & $1550^{\circ} \mathrm{C}$ & $1650^{\circ} \mathrm{C}$ & $1750^{\circ} \mathrm{C}$ \\
\hline 1. & Mullite-5 vol.\% SiC & 92.72 & 94.66 & 96.93 \\
2. & Mullite-10 vol.\% SiC & 91.49 & 93.31 & 93.98 \\
3. & Mullite-15 vol.\% SiC & 89.39 & 92.36 & 92.78 \\
4. & Mullite-20 vol.\% SiC & 86.78 & 88.96 & 89.04 \\
\hline
\end{tabular}

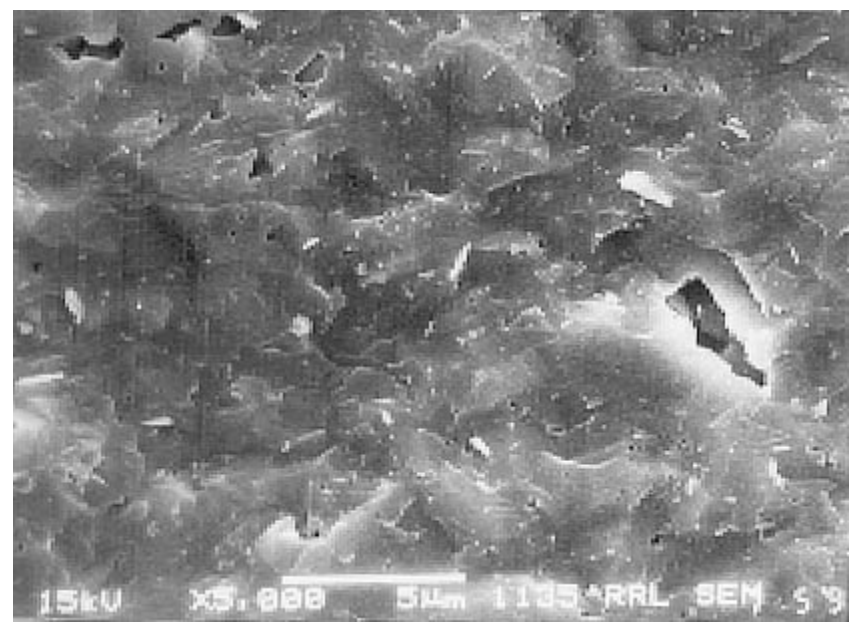

Figure 4. SEM fractograph of mullite-5 vol.\% SiC nanocomposites.

\subsection{Microstructural features}

The fractograph of the 5 vol.\% SiC incorporated mullite composite is presented in figure 4 . The coated precursor route had shown excellent dispersion characteristics with 5 vol.\% SiC. Silicon carbide particles of sizes around $200 \mathrm{~nm}$ appeared to have dispersed in mullite having grain size about 1-2 $\mathrm{m}$ and a high density. Random closed pores of submicron size were also seen. Under the present conditions of preparation the silicon carbide particle appear to get preferentially distributed at the grain boundaries and this could be a feature of the coated precursors. The dispersoid also exhibited a very good interface property. The fracture was often seen around the SiC particles, thus deciding the fracture mode. There appeared a strong influence for $\mathrm{SiC}$ particles in controlling the grain growth in the mullite, especially when placed at two opposite ends of a mullite grain. However, as the vol.\% of $\mathrm{SiC}$ dispersion increased, an increasing tendency for the segregation of the coated $\mathrm{SiC}$ particles was observed. The size of such aggregates varied in the range 1-2 $\mu \mathrm{m}$. This could have occurred due to the localized flocculation of the gel at the early stages of blending of the precursor. The room temperature microhardness in table 2 showed a decrease in the microhardness values with an increase in the percentage of $\mathrm{SiC}$ volume fractions. However, the
Table 2. Vicker's microhardness of mullite $\mathrm{SiC}$ nanocomposite.

\begin{tabular}{llc}
\hline $\begin{array}{l}\text { Sl. } \\
\text { no. }\end{array}$ & \multicolumn{1}{c}{ Samples } & $\begin{array}{c}V_{\mathrm{H}} \text { at } 500 \mathrm{~g} \\
\left(\mathrm{~kg} / \mathrm{mm}^{2}\right)\end{array}$ \\
\hline 1. & Mullite & 965 \\
2. & Mullite-5 vol.\% SiC & 1330 \\
3. & Mullite-10 vol.\% SiC & 1165 \\
4. & Mullite-15 vol.\% SiC & 965 \\
5. & Mullite-20 vol.\% SiC & 999 \\
\hline
\end{tabular}

incorporation of $\mathrm{SiC}$ increased the hardness value which was found to have almost doubled from $965 \mathrm{~kg} / \mathrm{mm}^{2}$ to $1330 \mathrm{~kg} / \mathrm{mm}^{2}$.

\section{Conclusions}

A well dispersed nanosized $\mathrm{SiC}$ in mullite composite by a coating technique was achieved. The sintered densities of the composites were found to decrease with increased volume \% of $\mathrm{SiC}$ at all sintering temperatures from 1550 $1750^{\circ} \mathrm{C}$, although qualitative observations indicated low levels of oxidation of the SiC phase. The Vicker's microhardness however, showed a maximum hardness of $1330 \mathrm{~kg} / \mathrm{mm}^{2}$ of the composite having only 5 vol.\% SiC. At a higher vol.\% of $\mathrm{SiC}$, the $\mathrm{SiC}$ particles were found to have dispersed at the grain boundaries, with agglomeration that had inhibited the grain growth.

\section{Acknowledgement}

The authors are thankful to Mr U S Haheesh, Technical University of Hamburg-Harburgh, for sintering of the samples.

\section{References}

Bhaduri S and Bhaduri S B 1998 J. Mater. 144

Choa Y H, Niihara A and Niihara K 1994 J. Am. Ceram. Soc. 773259

Hu C L and Rahaman M N 1992 J. Am. Ceram. Soc. 752056

Hu C L and Rahaman M N 1993 J. Am. Ceram. Soc. 762549 
Kanpuri N, Rai K N and Upadhyaya G S 1996 Ceram. Int. 106 14

Kapolnek D and De Jonghe L C 1991 J. Eur. Ceram. Soc. 7345

Komerneni S 1992 J. Mater. Chem. 21219

Mitchell T D and De Jonghe L C 1995 J. Am. Ceram. Soc. 78 199

Niihara K 1991 J. Ceram. Soc. Jpn. 99974

Pezzotti G and Saki M 1994 J. Am. Ceram. Soc. 773039
Saka Y, Bidinger D D and Aksay I A 1995 J. Am. Ceram. Soc. $\mathbf{7 8} 479$

Thompson A M, Chan H M, Harmer M P and Cook R F 1995 J. Am. Ceram. Soc. 78567

Warrier K G K, Hareesh U S, Anil Kumar G M and Damodaran A D 1996 Ceram. Trans. 68251

Wang C M 1996 J. Mater. Sci. 314709

Wang J, Ponton C B and Marquis P M 1996 Scr. Mater. 34935 